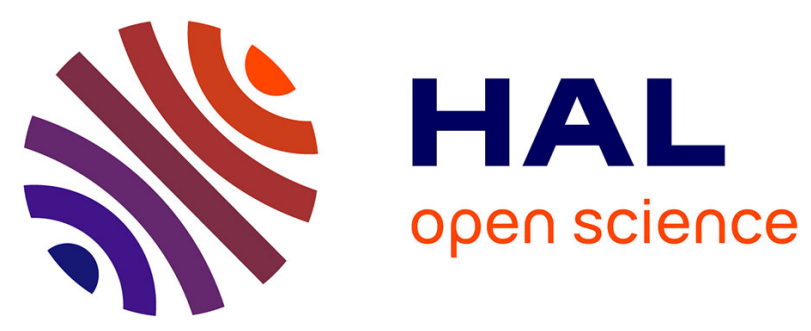

\title{
Mean stress dependent non linear hyperelasticity coupled with damage stiffness degradation. A thermodynamical approach
}

Solenn Le Pense

\section{- To cite this version:}

Solenn Le Pense. Mean stress dependent non linear hyperelasticity coupled with damage stiffness degradation. A thermodynamical approach. Mechanics Research Communications, 2014, 60, pp.8589. 10.1016/j.mechrescom.2014.06.007 . hal-01026475

\section{HAL Id: hal-01026475 \\ https: / hal-enpc.archives-ouvertes.fr/hal-01026475}

Submitted on 21 Jul 2014

HAL is a multi-disciplinary open access archive for the deposit and dissemination of scientific research documents, whether they are published or not. The documents may come from teaching and research institutions in France or abroad, or from public or private research centers.
L'archive ouverte pluridisciplinaire HAL, est destinée au dépôt et à la diffusion de documents scientifiques de niveau recherche, publiés ou non, émanant des établissements d'enseignement et de recherche français ou étrangers, des laboratoires publics ou privés. 
Author's version of a paper published in

Mechanics Research Communications, vol 60, pp 85-89 (2014). DOI: 10.1016/j.mechrescom.2014.06.007

Available at http://www.sciencedirect.com/science/article/pii/S0093641314000883

\title{
Mean stress dependent non linear hyperelasticity coupled with damage stiffness degradation. A thermodynamical approach
}

\author{
Solenn Le Pense \\ Université Paris-Est, Laboratoire Navier, CNRS, ENPC, IFSTTAR, Marne-La-Vallée, France
}

\begin{abstract}
Porous materials, such as geomaterials, exhibit a behaviour dependent on the confining pressure. The aim of this paper is to study the degradation of the elastic stiffness of mean stress dependent materials, due to the deterioration of the microstructure during loading.

Continuum damage mechanics offers a framework to model this rigidity deterioration. In addition to the concept of effective stress, a choice has to be made between two widely used hypotheses, the principle of strain equivalence and the principle of equivalent elastic energy, in order to build a complete modelling framework.

A mean stress dependent hyperelastic formulation is used to ensure a conservative behaviour, and associated to the two previous damage modelling assumptions, whose effects are compared. This allows for mean stress dependent elasticity to be reproduced, with elastic moduli increasing with mean stress while decreasing with damage.
\end{abstract}

Keywords:

Damage, Stiffness degradation, Principle of strain equivalence, Principle of equivalent elastic energy, Porous media

\section{Introduction}

Knowledge of geomaterials mechanical behaviour is of importance to accurately predict displacements encountered by underground structures during loading, for example tunnel convergence induced by excavation, or infrastructure settlements.

Usual elasto-plastic constitutive models for soils and rocks assume that the material behaves elastically for small strains. Although this assumption is idealistic, it is still reasonable, especially for overconsolidated clays, to consider an elastic domain in which the mechanical behaviour is reversible. Even for soils undergoing large plastic strains, the influence of the elastic part of the constitutive model should not be underestimated. Indeed, when modelling boundary value problems, the elastic component of the

Email address: solenn.le-pense@cermes .enpc.fr (Solenn Le Pense) 


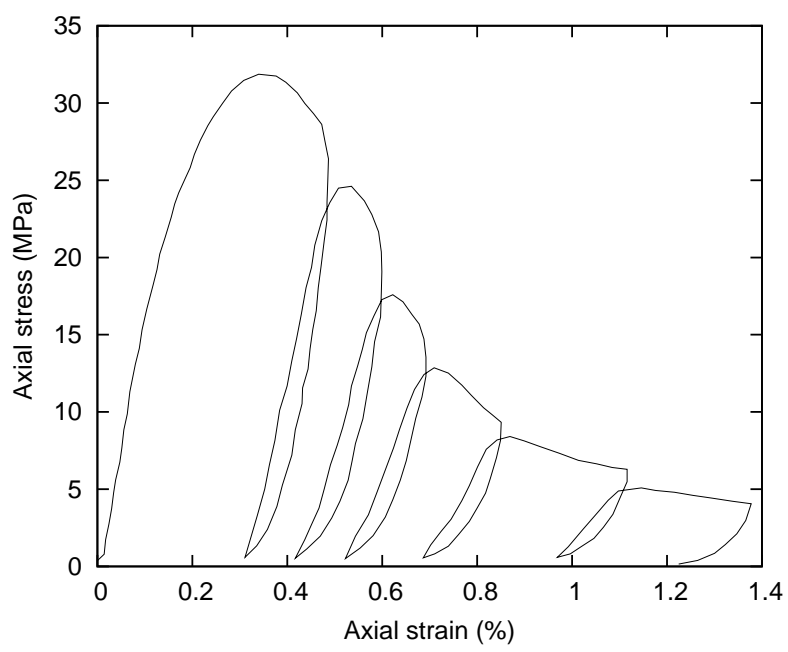

Figure 1: Typical stress-strain curve with unloading cycles during uniaxial compression test on concrete (from Burlion et al. (2005))

elastoplastic constitutive model determines the stress state of the soil at the onset of plasticity, which has a non negligible influence on the final plastic strains.

The small-strain stiffness of soils is known to be highly non-linear and has been experimentally studied extensively (Viggiani and Atkinson, 1995; Jovicic and Coop, 1997; Rampello et al., 1997; Atkinson, 2000; Callisto and Rampello, 2002). The small-strain shear modulus is usually assumed to depend on the stress state, the porosity (through the specific volume or the void ratio) and the loading history (through the overconsolidation ratio, the preconsolidation pressure or plastic strains). The initial increase of rigidity with mean stress (also referred to as the confining pressure in the following) can be attributed to the closure of pre-existing micro-cracks and micro-voids, and to pore compression. When undergoing large strains, the elastic rigidity decreases due to the creation and development of new micro-cracks and to the destructuration of cemented bonds. A typical stress-strain curve obtained during a uniaxial compression test on a concrete sample is given in figure 1.

In this paper we use a hyperelastic mean stress dependent formulation, in order to ensure thermodynamical consistency while accounting for the increase of moduli with mean stress. Continuum damage mechanics concepts are coupled to this hyperelastic formulation by following two different hypotheses, the principle of strain equivalence, introduced by Lemaitre and Chaboche (1978), and the principle of equivalent elastic energy, introduced by Cordebois and Sidoroff (1982). These two hypotheses have been widely used in the literature, and present different advantages and drawbacks. The impact of choosing one or the other of these hypotheses on the resulting material behaviour has been rarely studied, however.

This work will focus on how elastic rigidities evolve with damage for these two modelling assumptions. Rigidity expressions will be derived for different values of confining pressures and damage. Damage initiation and evolution will remain out of the scope of this paper.

\section{Degradation of geomaterials}

Modelling the degradation of geomaterials has received much interest in the last decade. Soils and rocks properties, such as rigidity, strength, or permeability, are known to be subject to changes after 
being submitted to hydric, mechanical, thermal or chemical solicitations. Several approaches have been used to model this degradation.

Some models have been developed using an approach called elastoplastic coupling. They assume elastic moduli to be functions of the amount of plastic strains (Hueckel, 1976; Sulem et al., 1999; Sulem and Ouffroukh, 2005; Gajo and Bigoni, 2008), and account for the loss of strength through the use of hardening plasticity. However, since they are based on the assumption that rigidity reduction happens simultaneously with plastic deformation, they are unable to represent independent development of damage and plasticity. It becomes then difficult to reproduce a change from a ductile to a more brittle behaviour due to modifications in the confining pressure or the water content.

Other models, developed for so-called structured, bonded or sensitive clays, focus on the increase in the size of the yield surface due to structure, which decreases at large strains to recover the yield surface of the reconstituted material (Rouainia and Muir wood, 2000; Kavvadas and Amorosi, 2000; Liu and Carter, 2002; Nova et al., 2003; Baudet and Stallebrass, 2004; Karstunen et al., 2005). A parameter is then introduced to account for the degradation of structure, which evolves with plastic strains in the aforementioned models. Most of these models do not account for the concomitant degradation of elastic rigidity. Moreover, these models are usually based on empirical observations, are not developed into a thermodynamical consistent framework and are designed to reproduce the behaviour of specific materials along specific stress paths.

Another approach, the one that is used in this paper, is to use the framework of Continuum Damage Mechanics, first developed for metals and later extended to concrete and rocks. This approach assumes that the degradation of material properties is due to the initiation and propagation of microcracks, and is based on the postulate of an effective stress, applied on the intact solid matrix, which controls the global material behaviour. Contrary to the previous approach, it allows damage and plastic strains to develop independently. It also enables the modelling of stiffness degradation and strength reduction simultaneously. This approach has been used to model a wide range of geomaterials, including concrete, hard rocks and structured clays (Rizzi and Loret, 1998; Chiarelli et al., 2003; Grassl and Jirásek, 2006; Einav et al., 2007; Arson and Gatmiri, 2009). It should be noted that damage can also be chosen to evolve with plastic strains within this modelling framework.

Concerning granular materials, a new family of models consider the crushing, or breakage, of grains submitted to compressive loads (Einav, 2007). However, the phenomena involved in particles crushing and the resulting effects on the material behaviour are different from the ones experienced by cemented geomaterials and solid porous media. The following developments will therefore be limited to this last category of materials.

\section{Mean-stress dependant hyperelasticity}

\subsection{Triaxial notations}

In the following, potentials are written in terms of triaxial variables, $\sigma$ being the stress tensor, $\varepsilon$ the strain tensor and $\mathbf{I}$ the identity matrix:

- Mean stress (confining pressure): $p=\frac{1}{3} \operatorname{tr}(\sigma)$

- Deviatoric stress: $q=\sqrt{\frac{3}{2} \sigma_{d}: \sigma_{d}}$, with $\sigma_{d}=\sigma-p \mathbf{I}$

- Volumetric strain: $\varepsilon_{v}=\operatorname{tr}(\varepsilon)$ 


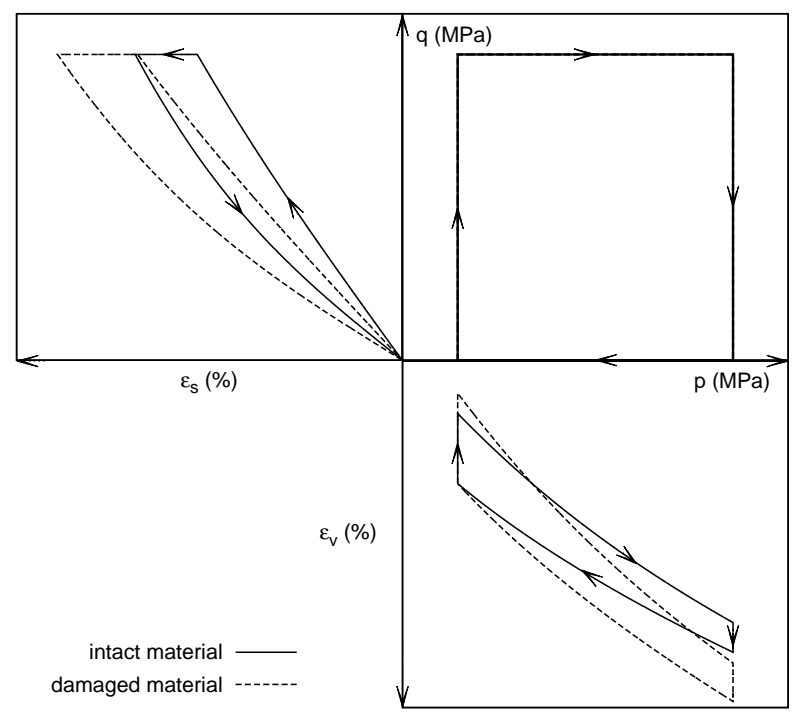

Figure 2: Comparison of volumetric and deviatoric strains during an elastic cycle for an intact and a damaged material

- Deviatoric strain: $\varepsilon_{s}=\sqrt{\frac{2}{3} \varepsilon_{d}: \boldsymbol{\varepsilon}_{d}}$, with $\boldsymbol{\varepsilon}_{d}=\boldsymbol{\varepsilon}-\frac{1}{3} \varepsilon_{v} \mathbf{I}$

\subsection{Mean-stress dependant hyperelasticity}

Experimental evidence show that bulk and shear moduli of geomaterials increase with confining pressure. An hypoelastic formulation is often used in association with Cam-Clay based plasticity models by assuming a constant Poisson's ratio. However, Zytynski et al. (1978) demonstrated that this leads to a non-conservative behaviour and eventually to permanent shear strains during cycling loading within the yield locus. For this reason, several researchers have been working on developing hyperelastic potentials from which constitutive stress-strain relationships should be derived (Loret, 1985; Houlsby, 1985; Borja et al., 1997; Sulem et al., 1999; Einav and Puzrin, 2004; Houlsby et al., 2005).

Deriving constitutive equations from potentials, considering mean stress dependent bulk and shear moduli, necessarily leads to a rigidity matrix comporting an additional coupling modulus, $J$ :

$$
\left\{\begin{array}{l}
d p \\
d q
\end{array}\right\}=\left[\begin{array}{cc}
K & J \\
J & 3 G
\end{array}\right]\left\{\begin{array}{l}
d \varepsilon_{v}^{e} \\
d \varepsilon_{s}^{e}
\end{array}\right\}
$$

The presence of the coupling modulus, $J$, results in stress induced anisotropy. This means that, even if the material properties are initially isotropic, a change in mean stress can create deviatoric strains, and that a change in deviatoric stress only can lead to volumetric strains (see figure 2).

Models are usually derived in a way to recover the following expression for the bulk modulus along the isotropic axis:

$$
\frac{K}{p_{r}}=\frac{1}{\kappa}\left(\frac{p}{p_{r}}\right)^{n}=k\left(\frac{p}{p_{r}}\right)^{n}
$$

in which $p_{r}$ is a reference pressure for which $K=k$, and the exponent $n$ is a material parameter allowing for the representation of different dependence of elastic moduli on the mean pressure. Linear elasticity is recovered for $n=0$, and Cam-clay elasticity for $n=1$. 
Of the works mentioned above, the only formulation for which the rigidity matrix is expressed entirely in terms of stresses is the one of Houlsby et al. (2005). Indeed, other formulations fail to determine the Gibbs potential complementary to the Helmholtz energy expressed in terms of strains. Since the following developments are based on the assumption of a damaged effective stress, coupling with damage is more straightforward when the rigidity matrix is expressed in terms of stresses instead of strains. We will therefore use this formulation in the following work. This formulation also allows some flexibility to choose how much moduli are dependent on the mean pressure by varying the value of the exponent $n$.

The Gibbs free energy is written as

$$
\mathcal{G}_{0}^{e}=\frac{p_{e}^{(2-n)}}{p_{r}^{(1-n)} k(1-n)(2-n)}-\frac{p}{k(1-n)}
$$

with $p_{e}^{2}=p^{2}+\frac{k(1-n) q^{2}}{3 g}$

in which $k$ and $g$ are material parameters such as, for the reference pressure $p_{r}, K\left(p_{r}\right)=k$ and $G\left(p_{r}\right)=g$.

The expressions of the different components of the rigidity matrix, $K, G$ and $J$, are derived from the Gibbs energy potential:

$$
\begin{gathered}
K=\left[1-\frac{n(1-n) k q^{2}}{3 g p_{e}^{2}}\right] k p_{r}^{(1-n)} p_{e}^{n} \\
G=\left[\frac{1}{1-\frac{n(1-n) k q^{2}}{3 g\left(p_{e}^{2}-n p^{2}\right)}}\right] g p_{r}^{(1-n)} p_{e}^{n} \\
J=n k p q p_{r}^{(1-n)} p_{e}^{(n-2)}
\end{gathered}
$$

\section{Hyperelastic formulations for damaged materials}

\subsection{Main damage modelling assumptions}

As damage increases, the resisting material section decreases due to the formation of microcracks. We consider that microcracks are isotropically distributed in the material, and that damage can be represented by a scalar variable, $d$, which represents an average of the proportion of damaged surfaces over a representative volume. The effective stress, which is the stress applied on the remaining intact material fraction was first introduced by Kachanov (1958):

$$
\tilde{\sigma}=\frac{\sigma}{1-d}
$$

To derive the elastic behaviour of the damaged materials, two main assumptions have been used in previous works:

- The principle of strain equivalence, which states that the strain associated with a damaged state under the applied stress is equivalent to the strain associated with its undamaged state under the effective stress (Lemaitre and Chaboche, 1978). It can be expressed as:

$$
\boldsymbol{\varepsilon}^{e}(\boldsymbol{\sigma}, d)=\boldsymbol{\varepsilon}^{e}(\tilde{\boldsymbol{\sigma}})=\frac{\partial \mathcal{G}_{0}^{e}(\tilde{\boldsymbol{\sigma}})}{\partial \tilde{\boldsymbol{\sigma}}}
$$


which can be derived from a Gibbs potential of the form:

$$
\mathcal{G}^{e}(\boldsymbol{\sigma}, d)=(1-d) \mathcal{G}_{0}^{e}(\tilde{\boldsymbol{\sigma}})
$$

- The principle of equivalent elastic energy which stipulates that the elastic energy of the damaged material is the same in form as that of an undamaged material except that the stress is replaced by the effective stress (Cordebois and Sidoroff, 1982). It can be expressed as:

$$
\mathcal{G}^{e}(\sigma, d)=\mathcal{G}_{0}^{e}(\tilde{\boldsymbol{\sigma}})
$$

which gives after derivation,

$$
\boldsymbol{\varepsilon}^{e}=\frac{\partial \mathcal{G}_{0}^{e}(\tilde{\boldsymbol{\sigma}})}{\partial \boldsymbol{\sigma}}=\frac{\partial \mathcal{G}_{0}^{e}(\tilde{\boldsymbol{\sigma}})}{\partial \tilde{\boldsymbol{\sigma}}} \frac{\partial \tilde{\boldsymbol{\sigma}}}{\partial \boldsymbol{\sigma}}=\frac{1}{1-d} \frac{\partial \mathcal{G}_{0}^{e}(\tilde{\boldsymbol{\sigma}})}{\partial \tilde{\boldsymbol{\sigma}}}
$$

Equations (8) and (11) are derived to obtain the incremental constitutive law,

$$
\frac{\partial \boldsymbol{\varepsilon}^{e}}{\partial \boldsymbol{\sigma}}=\frac{\partial \boldsymbol{\varepsilon}^{e}}{\partial \tilde{\boldsymbol{\sigma}}} \frac{\partial \tilde{\boldsymbol{\sigma}}}{\partial \boldsymbol{\sigma}}=\frac{1}{(1-d)} \frac{\partial \boldsymbol{\varepsilon}^{e}}{\partial \tilde{\boldsymbol{\sigma}}}
$$

and the expression of the damaged rigidity matrix:

$$
\mathbf{D}_{\mathbf{e}}(\sigma, d)=\left[\frac{1}{(1-d)} \frac{\partial \boldsymbol{\varepsilon}^{e}}{\partial \tilde{\sigma}}\right]^{-1}
$$

A summary of the forms taken by the previous equations for both principles is given in table 1

\subsection{Comparison of both approaches}

Hansen and Schreyer (1994) compared these two assumptions. In figure 3, damage is initiated at point 2 of the stress path 1-2-3. Point 7 denotes the effective state using the principle of strain equivalence. The stored energy associated with the final state, given by the area 1-3-6, is equated to the area in the effective space using the undamaged modulus, which is given by the area 1-5-4. This results in an effective state defined by an effective stress and an effective strain (point 5). The effective stress obtained by the principle of strain equivalence is much higher than the one for the principle of equivalent elastic energy. The choice between these two assumptions will therefore strongly influence the model behaviour.

For the linear elasticity case (i.e. $n=0), \mathbf{D}_{\mathbf{e}}(d)=(1-d) \mathbf{D}_{\mathbf{e}_{\mathbf{0}}}$ when assuming strain equivalence, and $\mathbf{D}_{\mathbf{e}}(d)=(1-d)^{2} \mathbf{D}_{\mathbf{e}_{0}}$ when assuming energy equivalence. So it is clear in this case that the apparent rigidity decreases with damage since the fraction of resisting material decreases, and the properties of the intact matrix remains constant. Most existing works about damage limit themselves to linear elasticity. However, in the mean stress dependent formulation, the evolution of the apparent rigidity with damage is not so straightforward. When damage increases, the effective stress on the resisting matrix will increase too. Since the elastic properties of this matrix are assumed to be mean stress dependent, the rigidity of the undamaged matrix will increase, which will partly counter-balance the loss of rigidity due to the decrease of effective surface.

To study the relative impact of these two phenomena, we will study the evolution of the ratio between apparent moduli and intact ones, noted as $R_{d}$. This ratio is the same for bulk, shear and coupling moduli. Details of its derivation are given is Appendix A. 


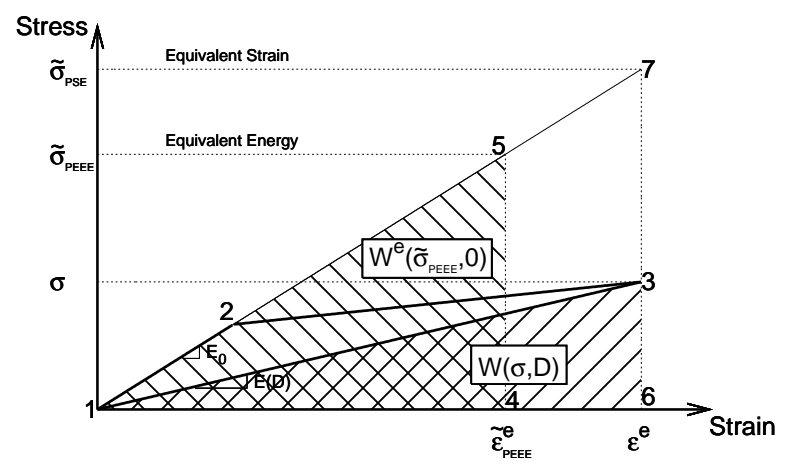

Figure 3: Difference between equivalent energy and strain equivalence principles (from Hansen and Schreyer (1994))

\begin{tabular}{lll}
\hline & PSE & PEEE \\
\hline $\mathcal{G}^{e}(\boldsymbol{\sigma}, d)=$ & $(1-d) \mathcal{G}_{0}^{e}(\tilde{\boldsymbol{\sigma}})$ & $\mathcal{G}_{0}^{e}(\tilde{\boldsymbol{\sigma}})$ \\
\hline $\boldsymbol{\varepsilon}^{e}=$ & $\frac{\partial \mathcal{G}_{0}^{e}(\tilde{\boldsymbol{\sigma}})}{\partial \tilde{\boldsymbol{\sigma}}}$ & $\frac{1}{1-d} \frac{\partial \mathcal{G}_{0}^{e}(\tilde{\boldsymbol{\sigma}})}{\partial \tilde{\boldsymbol{\sigma}}}$ \\
\hline$\frac{\partial \boldsymbol{\varepsilon}^{e}}{\partial \boldsymbol{\sigma}}=$ & $\frac{1}{1-d} \frac{\partial^{2} \mathcal{G}_{0}^{e}(\tilde{\boldsymbol{\sigma}})}{\partial \tilde{\boldsymbol{\sigma}}^{2}}$ & $\frac{1}{(1-d)^{2}} \frac{\partial^{2} \mathcal{G}_{0}^{e}(\tilde{\boldsymbol{\sigma}})}{\partial \tilde{\boldsymbol{\sigma}}^{2}}$ \\
\hline $\mathbf{D}_{\mathbf{e}}(\boldsymbol{\sigma}, d)=$ & $(1-d) \mathbf{D}_{\mathbf{e}_{\mathbf{0}}}(\tilde{\boldsymbol{\sigma}})$ & $(1-d)^{2} \mathbf{D}_{\mathbf{e}_{\mathbf{0}}}(\tilde{\boldsymbol{\sigma}})$ \\
\hline$R_{d}=$ & $(1-d)^{(1-n)}$ & $(1-d)^{(2-n)}$ \\
\hline
\end{tabular}

Table 1: Specific functions for the Principles of strain equivalence (PSE), and the principle of Equivalent energy (PEEE) 


$$
R_{d}=\frac{K(\sigma, d)}{K(\sigma, d=0)}=\frac{G(\sigma, d)}{G(\sigma, d=0)}=\frac{J(\sigma, d)}{J(\sigma, d=0)}
$$

The expression of $R_{d}$ as a function of $d$ and $n$, derived from equations 4, 5, 6 and 13, is given in table 1 for both assumptions.

The evolution of this ratio with damage is represented on figures 4 and 5 for different values of $n$.

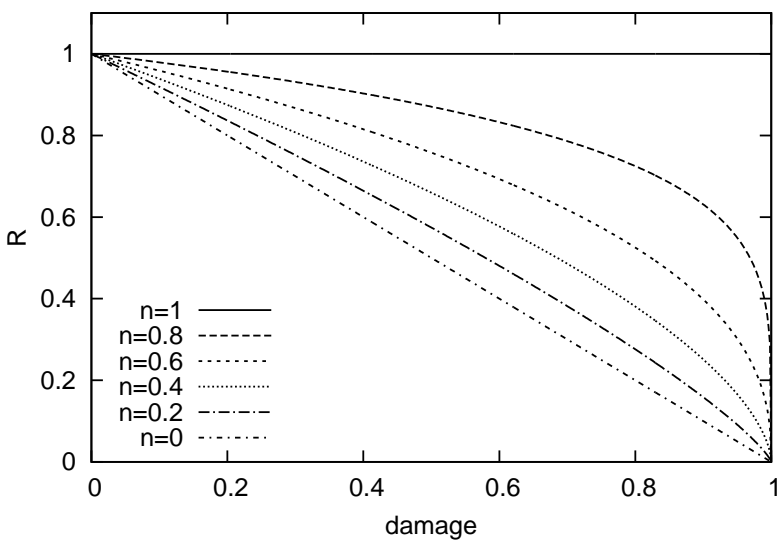

Figure 4: Effect of damage on apparent moduli for several pressure exponents - Principle of Strain equivalence

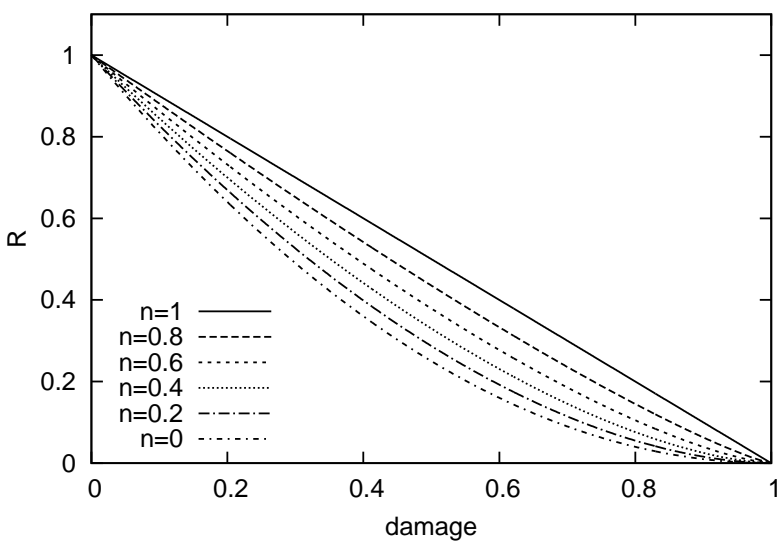

Figure 5: Effect of damage on apparent moduli for several pressure exponents - Principle of equivalent elastic energy

\section{Discussion and conclusion}

Figures 4 and 5 both show that the influence of damage on apparent moduli decreases when $n$ increases. It is due to the fact that when effective stresses increase, the rigidity of the intact matrix increases too, since it depends on the confining pressure. This phenomenon partly compensates the rigidity degradation due to the diminution of effective surface on which loads are applied. This result makes sense, assuming that the characteristic length of microcracks is much larger that the distance between pores in a porous material, and that the material in the intact portion of the matrix behaves like the intact material. We can also notice that this effect is much more important for the hypothesis of strain equivalence. 
Figure 6 shows the evolution of Callovo-Oxfordian argillite radial stiffness during triaxial compression tests as a function of radial strain, obtained by Chiarelli et al. (2003). The radial stiffness was obtained by calculating the slope of unloading-reloading loops and the material behaviour was assumed to be elasto-plastic with linear elasticity. This material showed a damaged radial stiffness attaining values as low as $40 \%$ of its original value. In order to make a proper comparison between the theory and experimental results, one would need to consider specific damage criterion and evolution law, as well as a plasticity model, in cases where the material experiences plastic strains. These components are out of the scope of this paper, which focuses on the behaviour differences induced by the choice of the damage modelling assumptions.

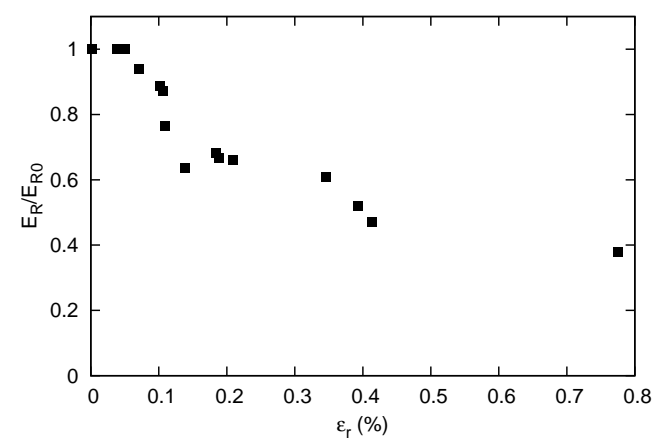

Figure 6: Evolution of radial stiffness during triaxial compression tests as a function of radial strain (Chiarelli et al., 2003)

Depending on the specific damage criteria and evolution laws used, the behaviour may become unstable for certain loading paths for values of damage inferior to 1 , and certain values of degradation will therefore never be reached. For a given value of the damage criterion, the principle of equivalent elastic energy predicts more rigidity degradation. Authors should therefore be careful when choosing modelling hypotheses, because there is a risk that the degradation of moduli observed experimentally may never be reproduced by constitutive models.

Both hypotheses have advantages and shortcomings. The principle of strain equivalence is based on easily understandable physical concepts, and its coupling with plasticity is straightforward. Indeed, stresses can then be replaced by effective stresses in the classical expressions of plasticity criteria and evolution laws. However, the principle of equivalent elastic energy has been proposed to overcome the difficulties caused by the extension to anisotropic damage. Indeed, the use of this principle has the advantage of providing symmetric secant stiffness matrices, which is not guaranteed by the principle of strain equivalence.

The study presented in this paper therefore gives further arguments to carefully choose either the principle of strain equivalence or the principle of equivalent energy, depending on the experimental measures of degradation available to models developers. Special care should therefore be taken when combining damage modelling principles with non linear elasticity, for example in the case of porous material, which behaviour is known to be mean stress dependent.

\section{Acknowledgements}

The author wish to thank Ahmad Pouya at Laboratoire Navier for his helpful comments on the paper. 


\section{Appendix A. Derivation of damaged quantities}

$$
\begin{aligned}
& \tilde{p}=\frac{p}{1-d} \\
& \tilde{q}=\frac{q}{1-d}
\end{aligned}
$$

$$
\tilde{p}_{e}^{2}=\left(\frac{p}{1-d}\right)^{2}+\frac{k(1-n)\left(\frac{q}{1-d}\right)^{2}}{3 g}=\frac{\tilde{p}_{e}^{2}}{(1-d)^{2}}
$$

$$
\begin{aligned}
K(\tilde{\boldsymbol{\sigma}}) & =\left[1-\frac{n(1-n) k\left(\frac{q}{1-d}\right)^{2}}{3 g\left(\frac{p_{e}}{1-d}\right)^{2}}\right] k p_{r}^{(1-n)}\left(\frac{p_{e}}{1-d}\right)^{n} \\
& =\frac{K(\sigma, d=0)}{(1-d)^{n}}
\end{aligned}
$$

$$
\begin{aligned}
G(\tilde{\boldsymbol{\sigma}}) & =\left[\frac{1}{1-\frac{n(1-n) k\left(\frac{q}{1-d}\right)^{2}}{3 g\left(\left(\frac{p_{e}}{1-d}\right)^{2}-n\left(\frac{p}{1-d}\right)^{2}\right)}}\right] g p_{r}^{(1-n)}\left(\frac{p_{e}}{1-d}\right)^{n} \\
& =\frac{G(\sigma, d=0)}{(1-d)^{n}}
\end{aligned}
$$

$$
\begin{aligned}
J(\tilde{\boldsymbol{\sigma}}) & =n k\left(\frac{p}{1-d}\right)\left(\frac{q}{1-d}\right) p_{r}^{(1-n)}\left(\frac{p_{e}}{1-d}\right)^{n-2} \\
& =\frac{J(\boldsymbol{\sigma}, d=0)}{(1-d)^{n}}
\end{aligned}
$$

PSE $: \frac{K(\sigma, d)}{K(\tilde{\boldsymbol{\sigma}})}=\frac{G(\boldsymbol{\sigma}, d)}{G(\tilde{\boldsymbol{\sigma}})}=\frac{J(\sigma, d)}{J(\tilde{\boldsymbol{\sigma}})}=(1-d)$

$\operatorname{PEEE}: \frac{K(\boldsymbol{\sigma}, d)}{K(\tilde{\boldsymbol{\sigma}})}=\frac{G(\boldsymbol{\sigma}, d)}{G(\tilde{\boldsymbol{\sigma}})}=\frac{J(\boldsymbol{\sigma}, d)}{J(\tilde{\boldsymbol{\sigma}})}=(1-d)^{2}$ 


\section{References}

Arson, C., Gatmiri, B., 2009. A mixed damage model for unsaturated porous media. Comptes Rendus Mécanique 337, 68-74. doi:10.1016/j.crme.2009.03.005.

Atkinson, J.H., 2000. Non-linear soil stiffness in routine design. Géotechnique 50, 487-508. doi:10.1680/geot.2000.50.5.487.

Baudet, B., Stallebrass, S., 2004. A constitutive model for structured clays. Géotechnique 54, $269-278$. doi:10.1680/geot.2004.54.4.269.

Borja, R.I., Tamagnini, C., Amorosi, A., 1997. Coupling Plasticity and Energy-Conserving Elasticity Models for Clays. Journal of Geotechnical and Geoenvironmental Engineering 123, 948-957. doi:10.1061/(ASCE)1090-0241(1997)123:10(948).

Burlion, N., Bourgeois, F., Shao, J., 2005. Effects of desiccation on mechanical behaviour of concrete. Cement and Concrete Composites 27, 367-379. doi:10.1016/j.cemconcomp.2004.05.004.

Callisto, L., Rampello, S., 2002. Shear strength and small-strain stiffness of a natural clay under general stress conditions. Géotechnique 52, 547-560. doi:10.1680/geot.2002.52.8.547.

Chiarelli, A.S., Shao, J., Hoteit, N., 2003. Modeling of elastoplastic damage behavior of a claystone. International Journal of Plasticity 19, 23-45. doi:10.1016/S0749-6419(01)00017-1.

Cordebois, J.P., Sidoroff, F., 1982. Endommagement anisotrope en élasticité et plasticité. Journal de Mécanique Théorique et Appliquée, Numéro Spécial 1, 45-60.

Einav, I., 2007. Breakage mechanics - Part I: Theory. Journal of the Mechanics and Physics of Solids 55, $1274-1297$. doi:10.1016/j.jmps.2006.11.003.

Einav, I., Houlsby, G.T., Nguyen, G.D., 2007. Coupled damage and plasticity models derived from energy and dissipation potentials. International Journal of Solids and Structures 44, 2487-2508. doi:10.1016/j.ijsolstr.2006.07.019.

Einav, I., Puzrin, A.M., 2004. Pressure-Dependent Elasticity and Energy Conservation in Elastoplastic Models for Soils. Journal of Geotechnical and Geoenvironmental Engineering 130, 81-92. doi:10.1061/(ASCE)1090-0241(2004)130:1(81).

Gajo, A., Bigoni, D., 2008. A model for stress and plastic strain induced nonlinear, hyperelastic anisotropy in soils. International Journal for Numerical and Analytical Methods in Geomechanics 32, 833-861. doi:10.1002/nag.648.

Grassl, P., Jirásek, M., 2006. Damage-plastic model for concrete failure. International Journal of Solids and Structures 43, 7166-7196. doi:10.1016/j.ijsolstr.2006.06.032.

Hansen, N.R., Schreyer, H.L., 1994. A thermodynamically consistent framework for theories of elastoplasticity coupled with damage. International Journal of Solids and Structures 31, 359-389. doi:10.1016/0020-7683(94)90112-0.

Houlsby, G.T., 1985. The use of a variable shear modulus in elastic-plastic models for clays. Computers and Geotechnics 1 , 3-13. doi:10.1016/0266-352X(85)90012-6.

Houlsby, G.T., Amorosi, A., Rojas, E., 2005. Elastic moduli of soils dependent on pressure: a hyperelastic formulation. Géotechnique 55, 383-392. doi:10.1680/geot.2005.55.5.383.

Hueckel, T., 1976. Coupling of elastic and plastic deformations of bulk solids. Meccanica 11, $227-235$. doi:10.1007/BF02128296.

Jovicic, V., Coop, M.R., 1997. Stiffness of coarse-grained soils at small strains. Géotechnique 47, 545-561. doi:10.1680/geot.1997.47.3.545.

Kachanov, L.M., 1958. Time of the rupture process under creep conditions. Isv. Akad. Nauk. SSR. Otd Tekh. Nauk 8, $26-31$.

Karstunen, M., Krenn, H., Wheeler, S.J., Koskinen, M., Zentar, R., 2005. Effect of Anisotropy and Destructuration on the Behavior of Murro Test Embankment. International Journal of Geomechanics 5, 87-97. doi:10.1061/(ASCE)15323641(2005)5:2(87).

Kavvadas, M.J., Amorosi, A., 2000. A constitutive model for structured soils. Géotechnique 50, $263-273$. doi:10.1680/geot.2000.50.3.263.

Lemaitre, J., Chaboche, J.1., 1978. Aspect phénoménologique de la rupture par endommagement. Journal de Mécanique Appliquée 2, 317-365.

Liu, M.D., Carter, J.P., 2002. A structured Cam Clay model. Canadian Geotechnical Journal 39, 1313-1332. doi:10.1139/t02069.

Loret, B., 1985. On the choice of elastic parameters for sand. International Journal for Numerical and Analytical Methods in Geomechanics 9, 285-292. doi:10.1002/nag.1610090308.

Nova, R., Castellanza, R., Tamagnini, C., 2003. A constitutive model for bonded geomaterials subject to mechanical and/or chemical degradation. International Journal for Numerical and Analytical Methods in Geomechanics 27, 705-732. doi:10.1002/nag.294.

Rampello, S., Viggiani, G.M.B., Amorosi, A., 1997. Small-strain stiffness of reconstituted clay compressed along constant triaxial effective stress ratio paths. Géotechnique 47, 475-489. doi:10.1680/geot.1997.47.3.475.

Rizzi, E., Loret, B., 1998. Constitutive modeling of fluid-saturated porous media with degrading elastic properties, in: Poromechanics: A Tribute to Maurice A. Biot, pp. 141-146. 
Rouainia, M., Muir wood, D., 2000. A kinematic hardening constitutive model for natural clays with loss of structure. Géotechnique 50, 153-164. doi:10.1680/geot.2000.50.2.153.

Sulem, J., Ouffroukh, H., 2005. Hydromechanical Behaviour of Fontainebleau Sandstone. Rock Mechanics and Rock Engineering 39, 185-213. doi:10.1007/s00603-005-0065-4.

Sulem, J., Vardoulakis, I., Papamichos, E., Oulahna, A., Tronvoll, J., 1999. Elastoplastic modelling of Red Wildmoor sandstone. Mechanics of Cohesive?frictional Materials 4, 215-245. doi:10.1002/(SICI)1099-1484(199905)4:3<215::AIDCFM61>3.0.CO;2-8.

Viggiani, G., Atkinson, J., 1995. Stiffness of fine-grained soil at very small strains. Géotechnique 45, $249-265$. doi:10.1680/geot.1995.45.2.249.

Zytynski, M., Randolph, M.F., Nova, R., Wroth, C.P., 1978. On modelling the unloading-reloading behaviour of soils. International Journal for Numerical and Analytical Methods in Geomechanics 2, 87-93. doi:10.1002/nag.1610020107. 